\title{
Estudio de la disolución de materia orgánica con dos presentaciones diferentes de hipoclorito de sodio
}

\section{Dissolution of organic matter with two different types of sodium hypochlorite}

\author{
María F Debiazi ${ }^{1}$, Georgette Arce Brisson ${ }^{1}$, Alejandro Marquez ${ }^{1}$, Gabriela Martin ${ }^{1}$ \\ 1Universidad Católica de Córdoba. Facultad de Ciencias de la Salud. Carrera de Especialización de Endodoncia. \\ Correspondencia: Debiazi María Florencia. Universidad Católica de Córdoba. Carrera de Endodoncia, Córdoba, Argentina; email: florenciadebiazi@ gmail.com
}

\section{Resumen}

INTRODUCCIÓN: En la terapéutica endodóntica el éxito depende no sólo de la instrumentación del sistema de conductos sino también de una adecuada limpieza y desinfección de este. La desinfección se logra a través de la irrigación del conducto y el irrigante más utilizado es el hipoclorito de sodio $(\mathrm{NaOCl})$, ya que presenta propiedades bactericida y bacteriostática, baja tensión superficial, $\mathrm{pH}$ alcalino, pero fundamentalmente porque es la única solución irrigante con capacidad para disolver el tejido orgánico. Se presenta en diferentes concentraciones de $0.5 \%$ al $6 \%$, y diferentes marcas comerciales de uso odontológico y doméstico.

OBJETIVO: Comparar 2 formas comerciales de $\mathrm{NaOCl}$ para disolver la materia orgánica en diferentes tiempos de exposición.

MATERIALES Y MÉTODOS: Se prepararon 20 trozos de tejido muscular bovino, los cuales fueron sumergidos durante 5, 10, 15, 20 minutos en una solución de $\mathrm{NaOCl}$. La muestra se dividió en 2 grupos $(\mathrm{n}=10)$ Grupo 1: $\mathrm{NaOCl}$ al 5.5\% de uso odontológico y Grupo 2: $\mathrm{NaOCl}$ de uso doméstico al 5.5\%. Cada trozo de carne fue pesado inicialmente en una balanza electrónica (Ohyo MP-300) y se registró en una tabla Excel. Posteriormente, se sumergió en $10 \mathrm{ml}$. de $\mathrm{NaOCl}$ durante 5 minutos. El mismo se retiró del $\mathrm{NaOCl}$, y se sumergió en solución fisiológica para eliminar e inactivar la solución de irrigación. Se secó con papel absorbente y se pesó en la balanza electrónica (Ohyo MP-300). Este procedimiento se repitió a los 10, 15 y 20 minutos, renovando la solución de irrigación para simular las condiciones clínicas y evitar saturación. Los datos recogidos fueron registrados y evaluados estadísticamente mediante la prueba de análisis con la variable de un factor (ANOVA).

RESULTADOS: El porcentaje de disolución de materia orgánica con $\mathrm{NaOCl}$ de uso odontológico fue similar al de uso doméstico a los 5, 10 y 15 minutos. A los 20 minutos con Tedequim se disolvió el 63,8\% de materia orgánica y con Ayudín el 69\%. Las diferencias no resultaron estadísticamente significativas CONCLUSIONES: Bajo las condiciones de este estudio se pudo concluir que tanto el $\mathrm{NaOCl}$ Tedequim como el Ayudín disolvieron la materia orgánica de manera similar en el tiempo, siendo el de uso doméstico de más fácil acceso y menor costo.

Palabras claves: Endodoncia, terapéutica de irrigación, hipoclorito de sodio, materia orgánica. 


\section{Abstract}

INTRODUCTION: The therapeutic endodontic success depends not only on the instrumentation of the root canal but also on proper cleaning and disinfecting of the canal system. Disinfection is achieved through the irrigation of the canal and the most widely used irrigation solution is sodium hypochlorite $(\mathrm{NaOCl})$, since it has bactericidal and bacteriostatic properties, low surface tension, alkaline $\mathrm{pH}$, but mainly because it is the only irrigation solution with the ability to dissolve organic tissue. It is presented in different concentrations from $0.5 \%$ to $6 \%$, and different commercial brands for dental and domestic use.

OBJECTIVE: To compare two commercial forms of $\mathrm{NaOCl}$ to dissolve organic matter at different times of exposure.

MATERIALS AND METHODS: we prepared 20 pieces of bovine muscle tissue, which were submerged for 5, 10, 15, 20 minutes in a $\mathrm{NaOCl}$ solution. The sample was divided into 2 groups $(\mathrm{n}=10)$ Group 1: dental $5.5 \% \mathrm{NaOCl}$ and Group 2: domesctic 5.5\% NaOCl. Each piece of meat was initially weighed on an electronic scale (Ohyo MP-300) and recorded in an Excel table. Subsequently, it was submerged in $10 \mathrm{ml}$. of $\mathrm{NaOCl}$ for 5 minutes. It was removed from $\mathrm{NaOCl}$ and immersed in physiological solution to eliminate and inactivate the irrigation solution. It was dried with absorbent paper and weighed on the electronic balance (Ohyo MP-300). This procedure was repeated at 10, 15 and 20 minutes, renewing the irrigation solution to simulate the clinical conditions and avoid saturation. In addition, the total dissolution time of the piece of meat will be recorded. The data collected was registered and assessed by means of the analysis test with the variable of a factor (ANOVA).

RESULTS: The percentage of dissolution of organic matter with $\mathrm{NaOCl}$ for dental use was similar to that for domestic use at 5, 10 and 15 minutes. At 20 minutes Tedequim dissolved $63.8 \%$ organic matter and Ayudín 69\%. The differences were not statistically significant.

CONCLUSION: Under the conditions of this study, it was concluded that both $\mathrm{NaOCl}$ Tedequim and Ayudín dissolved the organic matter in a similar time, being the domestic use of easy access and lower cost.

Key Words: Endodontic, irrigation therapeutic, sodium hypochlorite, organic matter.

\section{Introducción}

En la terapéutica endodóntica el éxito depende de una combinación de diferentes factores: preparación biomecánica, conformación, irrigación/aspiración, desinfección y obturación del conducto radicular ${ }^{1}$. Mediante varios estudios se ha demostrado que la instrumentación mecánica no puede proporcionar suficiente desinfección de los conductos radiculares ${ }^{2}$, ya que la complejidad del sistema de conductos, a menudo inaccesible a la instrumentación, dificulta aún más la deseada limpieza y desinfección del intricado espacio endodóntico ${ }^{3,4}$, dejando grandes áreas de la pared del conducto radicular sin ser tocadas por el instrumento ${ }^{5,6,7}$. Durante la preparación quirúrgica se generan limallas de dentina, las cuales, sumado a los restos orgánicos conforman el estrato ideal para el desarrollo del denominado biofilm, la cual juega un rol importante en el pronóstico endodóntico $8,9,10,11$.

Para aumentar la eficacia de la preparación mecánica, eliminar bacterias y remover tejido orgánico e inorgánico, la instrumentación debe complementarse con soluciones de irrigación ${ }^{3,12}$. Entre las soluciones usadas tanto en el pasado como en la actualidad, podemos citar la solución salina estéril, el hipoclorito de sodio $(\mathrm{NaOCl})$, los detergentes derivados del amonio cuaternario, clorhexidina, ácido cítrico y $\mathrm{EDTA}^{2}$. Las características de un irrigante ideal son: bactericida y/o bacteriostático, no deben lesionar los tejidos periapicales, por lo tanto, deben ser poco citotóxicos, solventes de tejido o residuos orgánicos e inorgániños, baja tenseón superficial, lubricantes, de fácol aplicación, acción rápida y sostenida, entre otras ${ }^{13}$

El irrigante más utilizado durante la terapia endodóntica es el $\mathrm{NaOCl}$ porque es efectivo para eliminar tejido vital y no vital, con un amplio efecto antibacteriano, destruyendo bacterias, hongos, esporas y virus, excelente lubricante y blanqueador, favoreciendo la acción de los instrumentos, vida media de almacenamiento prolongada y bajo costo ${ }^{14}$. Además, la baja tensión superficial que presenta permite su penetración a zonas de difícil acceso, como conductos laterales y túbulos dentinarios. $\mathrm{El} \mathrm{NaOCl}$ por sí solo no disuelve barro dentinario, pero sí la materia orgánica de la pulpa y de la predentina ${ }^{15}$. Por su poder antimicrobiano disminuye el número de bacterias dentro de los conductos laterales minimizando el riesgo de agudización, en consecuencia, incrementa el porcentaje de éxito de los tratamientos endodónticos ${ }^{16}$.

El hipoclorito de sodio $(\mathrm{NaOCl})$ por su $\mathrm{pH}$ alcalino ${ }^{11,8}$ neutraliza la acidez del medio creando un ambiente inadecuado para el desarrollo de

Revista Methodo: Investigación Aplicada a las Ciencias Biológicas. Universidad Católica de Córdoba. Jacinto

Ríos 571 Bo Gral. Paz. X5004FXS. Córdoba. Argentina. Tel.: (54) 3514517299 / Correo: methodo@ucc.edu.ar

/ Web: methodo.ucc.edu.ar | ARTICULO ORIGINAL Rev. Methodo 2020;5(2):48-55 
bacterias y se emplea en diferentes concentraciones que van del $0,5 \%$ al $5,25 \%{ }^{17}$. Cvek y col. (1976), Byströn y Sundquist (1985), Ferreira y col (1999) consideran que el $\mathrm{NaOCl}$ debe ser usado al $0,5 \%$ ya que es excelente antimicrobiano de baja toxicidad ${ }^{18,19,20}$, Spangberg y Engistrom (1968), Spangberg y col. (1979), Baungartner y Cvenin (1992) demostraron que el $\mathrm{NaOCl}$ al $1 \%$ es más agresivo, pero con mejor efecto antimicrobiano ${ }^{21,22,23}$. Cunningham y Balekjian (1980), Tartari y col (2016) concluyeron que una concentración de $2,5 \%$ es eficaz para disolver tejido necrótico, orgánico e inorgánico y reducir el número de bacterias, previniendo daños a nivel de la estructura de la dentina ${ }^{24,25}$. Grossman y Meinan (1941), Grossman (1981) recomendaba utilizar solución al 5\% mientras que Buck y col. (2001) y Diemer y col (2003) preferían al $5,25 \%$ 26,27,28,29.

Para mejorar las condiciones del $\mathrm{NaOCl}$ a la hora de la disolución de tejido orgánico, algunos autores recomiendan incrementar la temperatura de la solución de irrigación y activar la misma. Cabe señalar que el $\mathrm{NaOCl}$ al $1 \%$ a $45^{\circ} \mathrm{C}$ disuelve el tejido pulpar tan efectivamente como el $\mathrm{NaOCl}$ al $5,25 \%$ a temperatura ambiente $\left(20^{\circ} \mathrm{C}\right)$, por lo cual no se recomienda calentar la solución de $\mathrm{NaOCl}$ por un periodo prolongado, ya que está demostrado que el calentamiento por 24 horas genera perdida de iones cloro disminuyendo sus propiedades $^{24,30,31}$. Cuanto menor contenido de cloro tenga la solución de $\mathrm{NaOCl}$, menor será el $\mathrm{pH}$ del irrigante ${ }^{32}$.

La lavandina doméstica, disponible comercialmente, contiene $\mathrm{NaOCl}$ al $2.5 \%, 4.9 \%$, $5.5 \%$ y $6.15 \%$; presenta un $\mathrm{pH}$ alcalino de $11,4 \mathrm{y}$ es hipertónica. Algunos autores recomiendan la dilución del $\mathrm{NaOCl}$ comercial con bicarbonato al $1 \%$ en lugar de agua para ajustar el $\mathrm{pH}$ a un nivel inferior. Otros investigadores no han observado ninguna reducción en la capacidad nociva sobre el tejido sano con la neutralización del $\mathrm{NaOCl}$, y recomiendan diluir las soluciones de $\mathrm{NaOCl}$ con agua para obtener soluciones de irrigación menos concentradas ${ }^{2}$.

\section{Aspectos éticos}

En el tratamiento endodóntico la irrigación resultó ser de suma importancia, y la mayoria de los odontólogos en la práctica diaria usaron $\mathrm{NaOCl}$ de uso doméstico para la irrigación del conducto radicular, sin saber con exactitud su eficacia. En el presente estudio se planteó estudiar si el $\mathrm{NaOCl}$ de uso doméstico como el de uso exclusivo odontológico degradan de igual manera el tejido orgánico y en un tiempo similar, siendo el de uso doméstico más económico y de fácil acceso.

\section{Objetivo}

Comparar dos formas comerciales de hipoclorito de sodio para disolver la materia orgánica en diferentes tiempos de exposición

\section{Material y métodos}

Para esta investigación se utilizaron $1000 \mathrm{ml}$. de hipoclorito de sodio al 5,5\% preparado en laboratorio de uso odontológico (Tedequim), con las medidas exactas, conservada en botella de plástico color ámbar, previamente esterilizada, protegida de la luz y a temperatura ambiente.(Figura 1) Por otra parte, se usaron 1000 $\mathrm{ml}$. de hipoclorito de sodio al 5,5\% comercial de uso doméstico (Ayudín) para la cual se tuvo en cuenta ciertas características como: envase cerrado, con menos de 120 días de envasado y conservado a temperatura ambiente. (Figura 2)

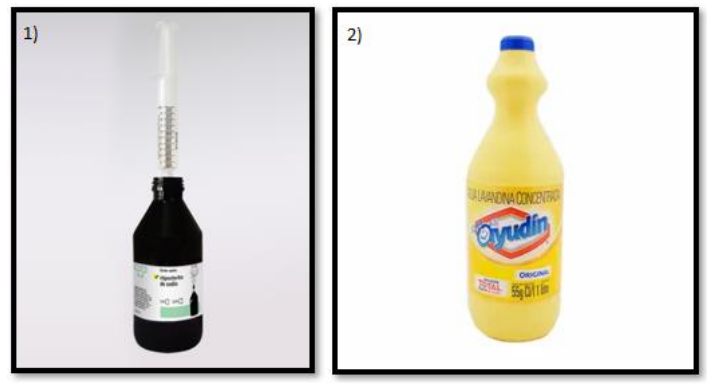

Figura 1 y 2. $\mathrm{NaOCl}$ Tedequim y $\mathrm{NaOCl}$ Ayudín.

Se utilizaron 20 trozos de tejido muscular bovino (carne bovina) como muestra de tejido orgánico, el cual se encontraban a temperatura ambiente. Estos se obtuvieron cortando con bisturí, piezas de $5 \times 5 \times 2 \mathrm{~mm}$ (ancho $\mathrm{x}$ grosor $\mathrm{x}$ largo) (Figura 3) La muestra se dividió en 2 grupos de 10 trozos cada uno $(\mathrm{n}=10)$, de acuerdo con la solución de irrigación:

- Grupo 1(G1): Hipoclorito de sodio al $5.5 \%$ (Ayudín).

- Grupo 2(G2): Hipoclorito de sodio al $5.5 \%$ (Tedequim, Industria Argentina, Córdoba) (Figura 4). 


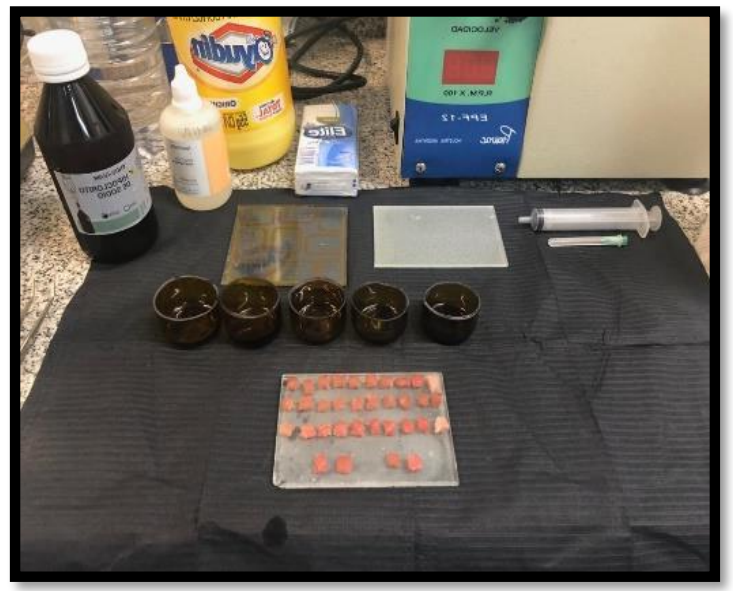

Figura 3. Mesa Clínica.

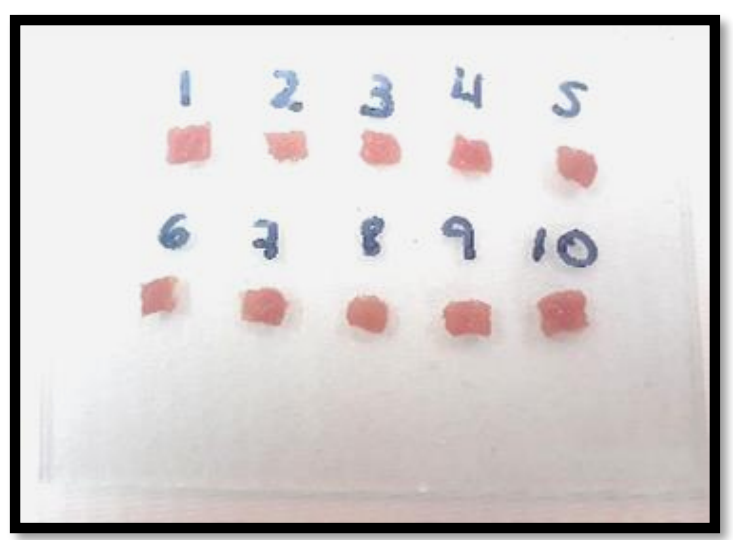

Figura 4. Trozos tejido muscular bovino.

Cada muestra fue pesada en una balanza electrónica (Ohyo MP-300) (Figura 5) y registrado el peso inicial (Figura 6). Posteriormente, fue sumergida en $10 \mathrm{ml}$. de $\mathrm{NaOCl}$ durante 5 minutos (Figura 7). La misma se retiró del $\mathrm{NaOCl}$, pasado el tiempo estipulado y fue inmersa en solución fisiológica para eliminar e inactivar la solución de irrigación. Se secó con papel absorbente y se pesó en la balanza electrónica (Ohyo MP-300). Este procedimiento se repitió 4 veces más, a los 10, 15 y 20 minutos renovando la solución de irrigación para simular las condiciones clínicas y evitar saturación.

El tiempo total de exposición de la materia orgánica a la solución de $\mathrm{NaOCl}$ fue de 20min., aunque se dejó en $\mathrm{NaOCl}$ hasta su disolución total (Figura 8)

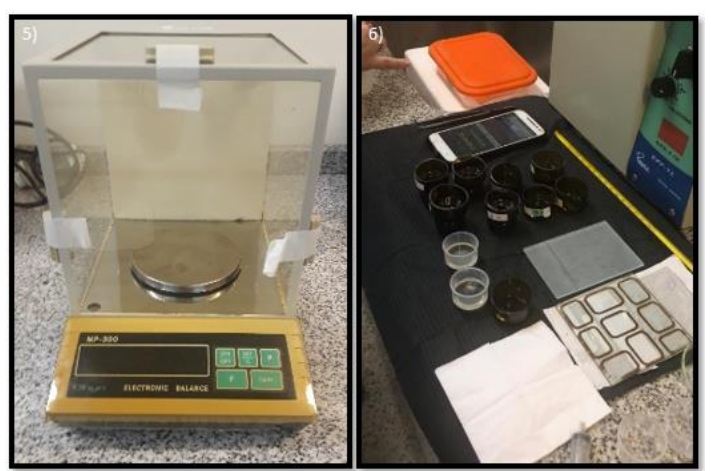

Figura 5 y 6. Balaza Ohyo MP-300 y Balanza electrónica

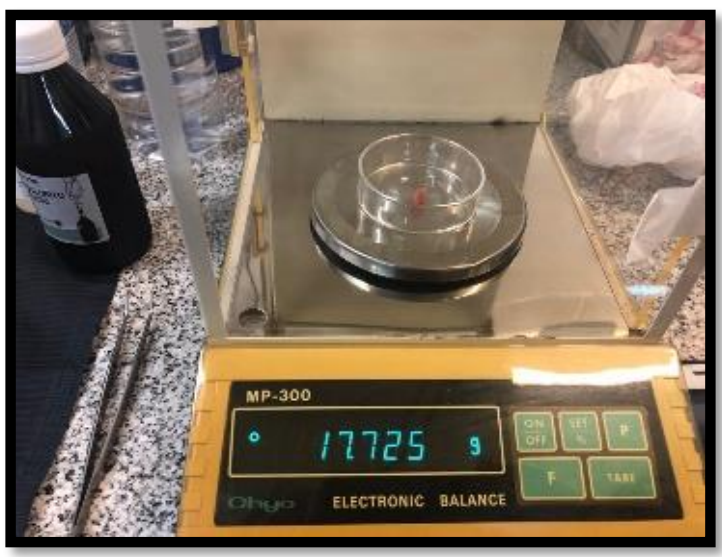

Figura 7. Mesa Clínica.

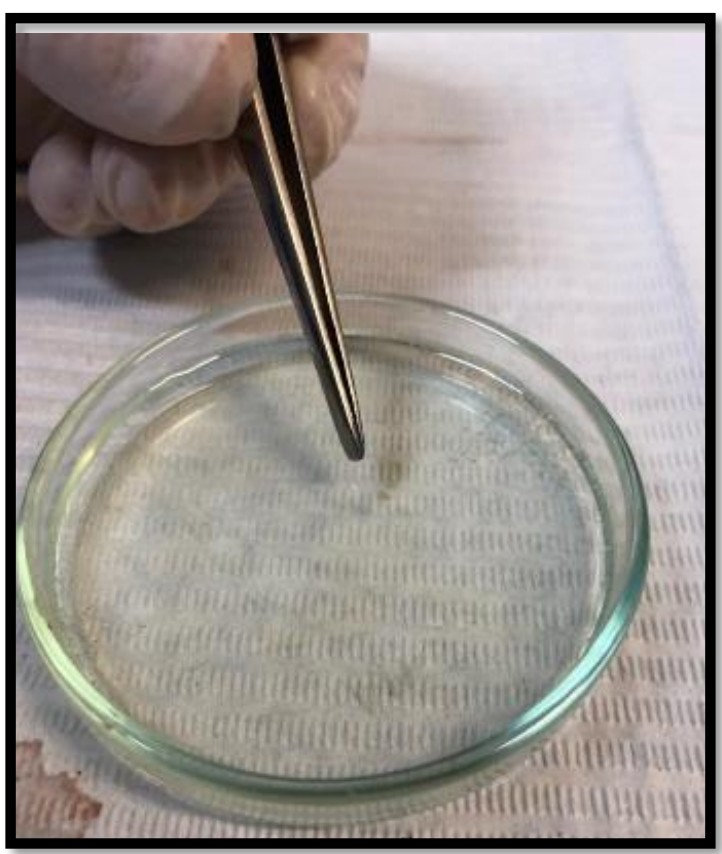

Figura 8. Muestra de la disolución. 


\section{Resultados}

En el presente estudio se evaluó el tiempo de disolución de tejido bovino frente a dos tipos diferentes de $\mathrm{NaOCl}$. En la Tabla 1 se registrarón los pesos obtenidos de cada muestra, en su etapa inicial, y a los 5, 10, 15 y 20 minutos.

A partir de los valores absolutos, se calculó el porcentaje de disolución de materia orgánica de cada una de las muestras, en los diferentes tiempos. En la tabla 2 se observa el porcentaje general de reducción tanto de Tedequin como de Ayudin a los $5 \mathrm{~min}, 10 \mathrm{~min}, 15 \mathrm{~min}$ y $20 \mathrm{~min}$ y el tiempo final de disolución total de la materia orgánica.

Tabla 1. Registro del peso de los trozos bovinos en la etapa inicial y en los diferentes tiempos de exposición al irrigante.

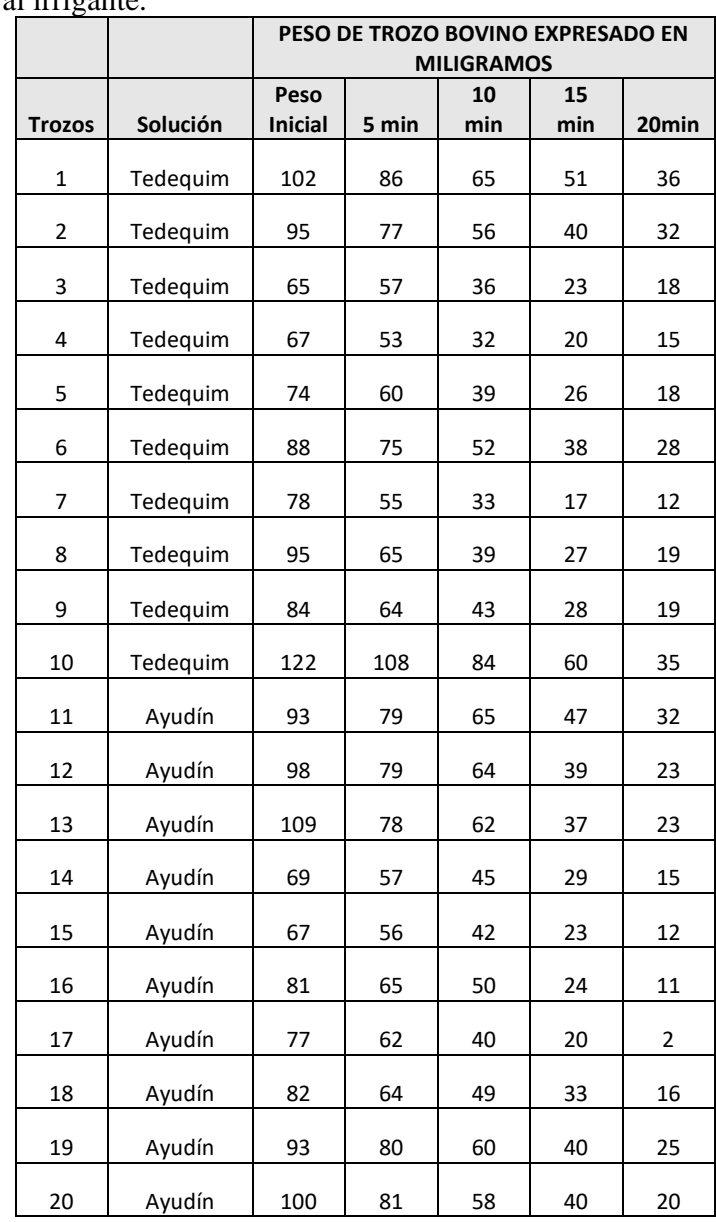

El porcentaje de disolución de materia orgánica con $\mathrm{NaOCl}$ de uso odontológico fue similar al de uso doméstico a los 5, 10 y 15 minutos. A los 20 minutos con Tedequim se disolvió el $63,8 \%$ de materia orgánica y con Ayudín el 69\% (Tabla 3).
Tabla 2. Porcentaje de reducción del peso de trozo bovino luego de ser sumergido en $\mathrm{NaOCl}$ Tedequim y Ayudín.

\begin{tabular}{|c|c|c|c|c|c|c|}
\hline \multicolumn{7}{|c|}{$\begin{array}{l}\text { PORCENTAJE DE REDUCCIÓN DE MATERIA } \\
\text { ORGÁNICA }\end{array}$} \\
\hline Trozos & $\mathrm{NaOCl}$ & $5 \mathrm{~min}$ & $\begin{array}{c}10 \\
\min \end{array}$ & $\begin{array}{c}15 \\
\min \end{array}$ & $\begin{array}{c}20 \\
\min \end{array}$ & $\begin{array}{l}\text { Tiemp } \\
\text { o final }\end{array}$ \\
\hline 1 & Tedequim & $\begin{array}{c}15,686 \\
2745 \\
\end{array}$ & $\begin{array}{c}36,274 \\
5098 \\
\end{array}$ & 50 & $\begin{array}{c}64,705 \\
8824 \\
\end{array}$ & $26: 14$ \\
\hline 2 & Tedequim & $\begin{array}{c}18,947 \\
3684\end{array}$ & $\begin{array}{c}41,052 \\
6316\end{array}$ & $\begin{array}{c}57,894 \\
7368\end{array}$ & $\begin{array}{c}66,315 \\
7895\end{array}$ & $18: 47$ \\
\hline 3 & Tedequim & $\begin{array}{c}12,307 \\
6923 \\
\end{array}$ & $\begin{array}{c}44,615 \\
3846 \\
\end{array}$ & $\begin{array}{c}64,615 \\
3846 \\
\end{array}$ & $\begin{array}{c}72,307 \\
6923 \\
\end{array}$ & 18:00 \\
\hline 4 & Tedequim & $\begin{array}{c}20,895 \\
5224\end{array}$ & $\begin{array}{c}52,238 \\
806 \\
\end{array}$ & $\begin{array}{c}70,149 \\
2537 \\
\end{array}$ & $\begin{array}{c}77,611 \\
9403 \\
\end{array}$ & 09:01 \\
\hline 5 & Tedequim & $\begin{array}{c}18,918 \\
9189 \\
\end{array}$ & $\begin{array}{c}47,297 \\
2973 \\
\end{array}$ & $\begin{array}{c}64,864 \\
8649 \\
\end{array}$ & $\begin{array}{c}75,675 \\
6757 \\
\end{array}$ & 13:05 \\
\hline 6 & Tedequim & $\begin{array}{c}14,772 \\
7273 \\
\end{array}$ & $\begin{array}{c}40,909 \\
0909\end{array}$ & $\begin{array}{c}56,818 \\
1818\end{array}$ & & $24: 00$ \\
\hline 7 & Tedequim & $\begin{array}{c}29,487 \\
1795\end{array}$ & $\begin{array}{c}57,692 \\
3077 \\
\end{array}$ & $\begin{array}{c}78,205 \\
1282 \\
\end{array}$ & $\begin{array}{c}84,615 \\
3846 \\
\end{array}$ & $11: 27$ \\
\hline 8 & Tedequim & $\begin{array}{c}31,578 \\
9474\end{array}$ & $\begin{array}{c}58,947 \\
3684\end{array}$ & $\begin{array}{c}71,578 \\
9474 \\
\end{array}$ & 80 & 23:53 \\
\hline 9 & Tedequim & $\begin{array}{c}23,809 \\
5238\end{array}$ & $\begin{array}{c}48,809 \\
5238\end{array}$ & $\begin{array}{c}66,666 \\
6667\end{array}$ & $\begin{array}{c}77,380 \\
9524\end{array}$ & $16: 30$ \\
\hline 10 & Tedequim & $\begin{array}{c}11,475 \\
4098 \\
\end{array}$ & $\begin{array}{c}31,147 \\
541\end{array}$ & $\begin{array}{c}50,819 \\
6721\end{array}$ & $\begin{array}{c}71,311 \\
4754 \\
\end{array}$ & $20: 39$ \\
\hline 11 & Ayudín & $\begin{array}{c}15,053 \\
7634\end{array}$ & $\begin{array}{c}30,107 \\
5269\end{array}$ & $\begin{array}{c}49,462 \\
3656\end{array}$ & $\begin{array}{c}65,591 \\
3978 \\
\end{array}$ & 29:00 \\
\hline 12 & Ayudín & $\begin{array}{c}19,387 \\
7551\end{array}$ & $\begin{array}{c}34,693 \\
8776\end{array}$ & $\begin{array}{c}60,204 \\
0816\end{array}$ & $\begin{array}{c}76,530 \\
6122\end{array}$ & $26: 00$ \\
\hline 13 & Ayudín & $\begin{array}{c}28,440 \\
367 \\
\end{array}$ & $\begin{array}{c}43,119 \\
2661 \\
\end{array}$ & $\begin{array}{c}66,055 \\
0459 \\
\end{array}$ & $\begin{array}{c}78,899 \\
0826 \\
\end{array}$ & 21:48 \\
\hline 14 & Ayudín & $\begin{array}{c}17,391 \\
3043\end{array}$ & $\begin{array}{c}34,782 \\
6087 \\
\end{array}$ & $\begin{array}{c}57,971 \\
0145\end{array}$ & $\begin{array}{c}78,260 \\
8696\end{array}$ & 19:15 \\
\hline 15 & Ayudín & $\begin{array}{c}16,417 \\
9104 \\
\end{array}$ & $\begin{array}{c}37,313 \\
4328 \\
\end{array}$ & $\begin{array}{c}65,671 \\
6418 \\
\end{array}$ & $\begin{array}{c}82,089 \\
5522 \\
\end{array}$ & $10: 46$ \\
\hline 16 & Ayudín & $\begin{array}{c}19,753 \\
0864 \\
\end{array}$ & $\begin{array}{c}38,271 \\
6049 \\
\end{array}$ & $\begin{array}{c}70,370 \\
3704 \\
\end{array}$ & $\begin{array}{c}86,419 \\
7531 \\
\end{array}$ & $10: 37$ \\
\hline 17 & Ayudín & $\begin{array}{c}19,480 \\
5195 \\
\end{array}$ & $\begin{array}{c}48,051 \\
9481 \\
\end{array}$ & $\begin{array}{c}74,025 \\
974 \\
\end{array}$ & $\begin{array}{c}97,402 \\
5974 \\
\end{array}$ & $06: 42$ \\
\hline 18 & Ayudín & $\begin{array}{c}21,951 \\
2195\end{array}$ & $\begin{array}{c}40,243 \\
9024\end{array}$ & $\begin{array}{c}59,756 \\
0976\end{array}$ & $\begin{array}{c}80,487 \\
8049\end{array}$ & $10: 52$ \\
\hline 19 & Ayudín & $\begin{array}{c}13,978 \\
4946\end{array}$ & $\begin{array}{c}35,483 \\
871\end{array}$ & $\begin{array}{c}56,989 \\
2473 \\
\end{array}$ & $\begin{array}{c}73,118 \\
2796 \\
\end{array}$ & $15: 30$ \\
\hline 20 & & 19 & 42 & 60 & 80 & $12: 35$ \\
\hline
\end{tabular}

Tabla 3. Porcentaje general de reducción.

\begin{tabular}{|c|c|c|c|c|}
\hline $\mathbf{N a O C l}$ & $\mathbf{5} \mathbf{~} \mathbf{m}$ & $\mathbf{1 0} \mathbf{~} \mathbf{~ i n}$ & $\mathbf{1 5} \mathbf{~ m i n}$ & $\mathbf{2 0} \mathbf{~}$ in \\
\hline TEDEQUIM & $17 \%$ & $39,1 \%$ & $54 \%$ & $63,8 \%$ \\
\hline AYUDIN & $16,8 \%$ & $33,4 \%$ & $53,7 \%$ & $69 \%$ \\
\hline
\end{tabular}

En la Figura 9 se observa mediante gráfico de barras, una dirferencia a los $10 \mathrm{~min}$. entre el $\mathrm{NaOCl}$ Tedequim sobre el $\mathrm{NaOCl}$ Ayudín, mientras que a los 20 min. la diferencia fue mayor para Ayudín. 


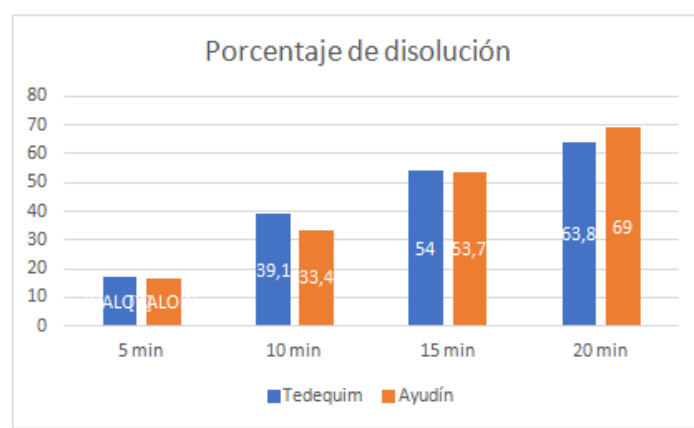

Figura 9. Gráfico de porcentaje de reducción.

A partir de los datos obtenidos a los 20 minutos, se tomó el tiempo final de disolución de la materia orgánica. En la tabla 4 se observa un promedio del tiempo final de disolución registrada a partir de los 20 minutos evaluados.

Tabla 4. Promedio de tiempo final de disolución de materia orgánica.

\begin{tabular}{|c|c|}
\hline NaOCI & Promedio Tiempo final \\
\hline Tedequim & $18: 10$ \\
\hline Ayudín & $16: 19$ \\
\hline
\end{tabular}

El promedio de tiempo final de disolución de materia organica con Tedequim fue 18:10 minutos a partir de los últimos 20 minutos registrados y con Ayudín fue de 16:19 minutos (Figura 10).

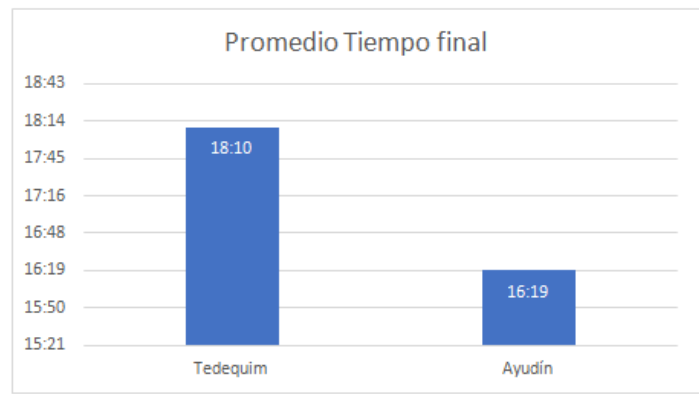

Figura 10. Grafico Promedio de Tiempo de disolución total de materia orgánica.

Los datos obtenidos fueron analizados estadisticamente por medio del Test ANOVA a medidas repetidas, y como se observa en la tabla 2 , se destacó que no presentó una diferencia significativa en el uso de ambos productos $(\mathrm{p}=0,986)$ y hubo un incremento en la degradación de tejido a lo largo del tiempo $(\mathrm{p}<0,001)$

Tabla 2. Test ANOVA

\begin{tabular}{|c|c|c|c|c|c|}
\hline $\begin{array}{c}\text { Fuente de } \\
\text { variación }\end{array}$ & $\begin{array}{c}\text { Suma } \\
\text { de los } \\
\text { cuadra } \\
\text { dos }\end{array}$ & $\begin{array}{c}\text { D } \\
\text { F }\end{array}$ & $\begin{array}{c}\text { Media } \\
\text { cuadrad } \\
\mathbf{a}\end{array}$ & F & P \\
\hline $\begin{array}{c}\text { Grupos (N } \\
\text { aOCl) }\end{array}$ & 0,250 & 1 & 0,250 & 0,000 & 0,98 \\
\hline Residual & 13398, & 18 & 744,348 & & 6 \\
\hline & 260 & & & & \\
\hline
\end{tabular}

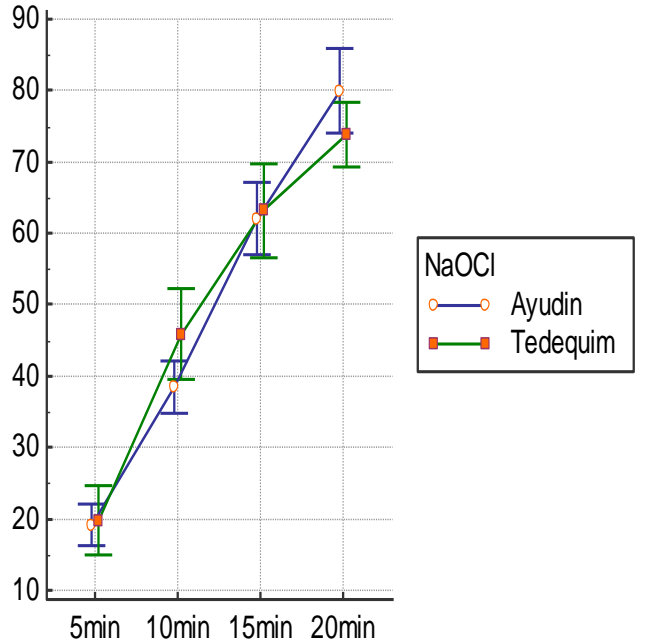

Figura 10. Gráfico del incremento de degradación de tejido.

\section{Discusión}

Dentro de las soluciones utilizadas actualmente en el tratamiento endodóntico, las soluciones de hipoclorito de sodio en diferentes concentraciones son las más usadas y mundialmente aceptadas por sus propiedades de clarificación, disolución de tejido orgánico, saponificación, transformación de aminoácidos en cloraminas $\mathrm{o}$ en sales de aminoácidos, desodorización y acción antimicrobiana ${ }^{24}$. En el presente estudio se observó que tanto el $\mathrm{NaOCl}$ al $5,5 \%$ de uso doméstico Ayudín como el $\mathrm{NaOCl}$ al $5,5 \%$ de uso odontológico Tedequim lograron disolver la materia orgánica, de igual manera. En un estudio realizado observaron que el $86.9 \%$ de los endodoncistas entrevistados, usan el $\mathrm{NaOCl}$ directamente de la botella ya sea de uso odontológico o bien de uso doméstico y que utilizan un protocolo para llegar a la concentración que emplean en la irrigación de conductos en la práctica clínica, evaluaban la concentración real de cloro activo en los envases mediante titulación yodométrica y no pudieron asegurar que la concentración que utilizan en su práctica clínica sea la que ellos desean utilizar o la adecuada para la irrigación de conductos radiculares, ya que la concentración que figura en el envase no es la correcta $^{33}$. En otros estudios mostraron que el $\mathrm{NaOCl}$ al $1 \%$ a $45^{\circ} \mathrm{C}$ disuelve el tejido pulpar tan efectivamente como el $\mathrm{NaOCl}$ al $5,25 \%$ a temperatura ambiente $\left(20^{\circ} \mathrm{C}\right)$, por lo cual no se recomienda calentar la solución de $\mathrm{NaOCl}$ por un periodo prolongado, ya que está demostrado que el calentamiento por 24 horas genera perdida de iones cloro disminuyendo sus propiedades ${ }^{24,30,31}$. Cuanto menor contenido de cloro tenga la solución 
de $\mathrm{NaOCl}$, menor será el $\mathrm{pH}$ del irrigante ${ }^{32}$. En el presente estudio se tuvo en cuenta que la solución de $\mathrm{NaOCl}$ de uso odontológico Tedequim fue preparada y envasada una semana antes de ser utilizada, siendo que el $\mathrm{NaOCl}$ de uso doméstico Ayudín, fue adquirido en el supermercado y llevaba ya un tiempo envasado y almacenado antes de su uso, lo que nos indicaría que con el paso del tiempo se inactivan los iones de cloro, y podríamos suponer basándonos en el estudio antes mencionado que el $\mathrm{NaOCl}$ de uso doméstico Ayudín presentaba al momento de envasado mayor cantidad de cloro activo, que se fue inactivando con el paso del tiempo.

En nuestro estudio coincidimos con el estudio de Tartari y $\mathrm{col}^{29}$. que confirman que se promueve la disolución de tejido en contacto con la solución en tiempo más prolongado y mayor concentración de $\mathrm{NaOCl}$.

\section{Conclusión}

Los resultados de este estudio nos permiten concluir que tanto el $\mathrm{NaOCl}$ de uso exclusivo odontológico Tedequim, como el $\mathrm{NaOCl}$ de uso doméstico Ayudín, sin ningún tipo de disolución, extraído directo de botella, se comportaron de igual manera, en el mismo período de tiempo, siendo el Ayudín el que actuó más rápido en la disolución total de la materia orgánica.

Debido al tiempo total de disolución es necesario el recambio continuo del irrigante y el contacto permanente con la materia orgánica en un tiempo aproximado de 40 minutos.

En la actualidad, no todos los pueblos y ciudades del país presentan casas dentales para adquirir el $\mathrm{NaOCl}$ preparado por un laboratorio exclusivo para uso odontológico, siendo el $\mathrm{NaOCl}$ de uso doméstico de fácil acceso y más económico.

\section{Bibliografía}

1. Schilder H (1974). Cleaning and shaping the root canal. Dent Clin North Am. 18:269-96.

2. Cohen S, Hargreaves K (2011) Vías de la pulpa. 10ma Edición. Barcelona, España.

3. Xu G, Zhang Z (1984) Filling of the lateral canal. Oral Surg. Oral Med. Oral Radiol. Endod. 58:221-4

4. Usman N, Baumgartner JC, Marshall JG (2004) Influence of instrument size on root canal debridement. J. Endod. 30:110-2

5. Vertucci FJ (2005) Root canal morphology and its relationship to endodontic procedures. Endodontic Topics. 10:3-29
6. Ricucci D, Siqueira JF (2010) Fate of the tissue in lateral canals and apical ramifications in response to pathology conditions and treatment procedures. J. Endod. 36:1-15

7. Fornari VJ, Silva- Sousa YT, Vanni JR, Pecora JD, V et al. (2010) Histological evaluation of the effectiveness of increased apical enlargement for cleaning the apical hird of curved canals. Int. Endod. J. 43:988-94

8. McComb D, Smith Dc (1975) A preliminary scanning electron microscopic study of root canal after endodontic procedures. J. Endod. $1: 238-242$

9. Desai P, Himel V (2009) Comparative saferty of intracanal irrigation systems. J. Endod. $35: 545-549$

10. Brito PR, Souza LC, de Oliveira JCM, Siqueira JF Jr. Et al. (2009) Comparison of thre effectivenes of three irrigation techniques in reducing intracanal enterococcus faecalis populations: an in vitro study. J. Endod. 35:1422-1427

11. Howard RK, Kirkpatrick TC, Rutledge RE, Yaccino JM (2011) Comparison of debris renoval with three different irrigation techniques. J. Endod. 37:1301-1305

12. Siqueira JF. Rocas IN (2008) Clinical implications and microbiology of bacterial persistence after treatment procedures. J. Endod. 34: 1291-301.

13. Masataka Y. Koichi Y (1996) Root canal irrigation citric acid solition. J. Endod. 22:2729

14. Azuero M, Herrera C. (2003) Irrigantes de uso odontológico. Pontificia Universidad Javariana. Colombia 2003

15. Torabinejad M, Khademi A. (2003) A new solution for the removal of the smear layer. J. Endod. 29: 170-175

16. Rodriguez H.I, Rodriguez S.M, Rodriguez M.E (2004) Uso de sustancias irrigadoras complementarias en endodoncia para la eliminación de la capa de barro dentinario propuesta de un protocolo de irrigación. ODOUS Cientifica, vol 1.

17. Canalda C (2001) Medicación intraconducto en endodoncia: técnica clínica y bases científicas. 184-193

18. Cvek M, Hollender L, Nord CE (1976) Treatment of non-vital permanent incisors with calcium hidroxide VI aclínica micribiological and radiological evaluation of 
treatment in one sitting of teeth with nature or innature root. Odontol Revy. 27:93-108

19. Bytröm A,Sundquist G, (1985) The antibacterial action of sodium hipochlorite and EDTA in 60 case of endodontic therapy. Int. Endod. J. 18:35-40

20. Ferreira C, Cortes B, Fröner I, Iti I (1999) Evaluation of the antimicrobial activity of the three irrigating solutions in teeth with pulpal necrosis. Braz Dent. J. 10:1-6

21. Spangberg L, Engstrom B (1968) Studies on root canal medicament. IV antimicrobial effect of root canal medicaments. Odontol Revy. 19:187-195

22. Spangberg L, Rutberg M, Rydinge E (1979) Biologic effects of endodontic antimicrobial agents. J. Endod. 5: 166-175

23. Baumgartner JC, Cvenin PR (1992) Efficacy of several concentration of sodium hipochlorite for root canal irrigation. J. Endod. 18:605-612

24. Cunningham WT, Balekjian AY (1980) Effect of temperatura on collagen dissolving ability of sodium hipochlorite endodontic irrigant. Oral Surg. 50:569-569

25. Tartari T, Bactmann L, Maliza AG, Bombardo $F$ et al. (2016) Tissue dissolution and modifications in dentin composition by diferente sodium hipochlorite concentrations. J. Appl. Oral.24:291-298

26. Grossman LI, Meiman B (1941) Solution of pulp tissue by chemical agents. J. Am. Dent. Assoc: 28:223-225

27. Grossman LI (1981) Practica Endodóntica. 4ta. Edición. Mundi. Buenos Aires.

28. Buck RA, Eleaser PD, Staal RH, Scheetz JP (2001) Effectiveness of three endodontic irrigants al various tubular depths in human dentin. J. Endod. 27:206-208

29. Diener WC, McClanahan SB, Milley GA (2003) The effect of passive ultrasonic activation of $2 \%$ clorhexidine or $5,25 \%$ sodium hipochlorite irrigant on residual antimicrobial activity in root canal. J. Endod. 29:562-564

30. Haapasalo M, Wang Z, Sheri Y, Curtis A et al. (2014) Tissue dissolution by novel multisonic ultracleaning sustem and sodium hypochlorite. J. Endod. 40:1178-1181

31. Sirtes G, Waltimo T, Schaetzle M, Zehder M (2005) The effects of temperture on sodium hypochlorite, short- term stability Pulp. Dissolution capacity and antimicrobial efficacy. J. Endod.31:669-671

32. Clarkson RM, Moule AJ, Podlich HM (2001) The shelf- live of sodium hypochlorite irrigating solutions. Australiam Dental J.46:269-276

33. Cárdenas Bahena A, Sánchez García S (2012) Hipoclorito de sodio en irrigación de conductos radiculares: Sondeo de opinión y concentración en productos comerciales. Rev. Odont. Mex. Vol. $16 \mathrm{~N}^{\circ} 4$.

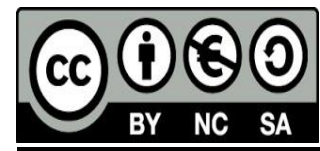

